\title{
Incidence and risk factors of delirium in multi-center Thai surgical intensive care units: a prospective cohort study
}

Tanyong Pipanmekaporn ${ }^{1 *}$, Kaweesak Chittawatanarat ${ }^{2}$, Onuma Chaiwat ${ }^{3}$, Thammasak Thawitsri ${ }^{4}$, Petch Wacharasint ${ }^{5}$, Suneerat Kongsayreepong ${ }^{3}$ and THAI-SICU Study Group

\begin{abstract}
Background: Delirium in intensive care units increases morbidity and mortality risk. The incidence and risk factors of delirium vary among studies. This study therefore aimed to determine the incidence and risk factors of delirium in Thai university-based surgical intensive care units.
\end{abstract}

Methods: A multi-center, prospective cohort study was conducted. All patients who had been admitted to surgical intensive care units (SICU) between April 2011 and January 2012 were enrolled. Delirium was diagnosed using the Intensive Care Delirium Screening Checklists (ICDSC). The univariable and multivariable risk regression analyses were analyzed and presented as risk ratio (RR) and $95 \%$ confidence interval $(\mathrm{Cl})$.

Results: The overall incidence of delirium was $3.6 \%$ (162 of 4450, $95 \% \mathrm{Cl} 3.09-4.19 \%$ ) whilst the incidences of delirium for patients being admitted $\leq 48$ and $>48 \mathrm{~h}$ were $0.7 \%$ (21 of $2967,95 \% \mathrm{Cl} 0.41-1.01 \%$ ) and $8.3 \%$ (141 of $1685,95 \% \mathrm{Cl} 7.04-9.68 \%$ ), respectively. The incidence of delirium on each study site was significantly different (range between 0 and $13.9 \%, P<0.001)$. Delirious patients had a significantly higher age $(65.3 \pm 15.6$ versus $61.8 \pm$ 17.3 years, $P=0.013$ ), higher Acute Physiology and Chronic Health Evaluation II score (APACHE II score) (16 (12-23) versus $10(7-15), P<0.001)$, and higher sequential organ failure assessment score $(5(2-8)$ versus $2(1-5), P<0.001)$. The median duration of delirium was $3(1-5)$ days. Delirious patients had significantly longer duration of ICU stay (8 (5-19) versus $2(1-4), P<0.001)$ and higher ICU mortality rate $(23.5$ versus $8.1 \%, P<0.001)$. Sepsis $(R R=3.70,95 \%$ $\mathrm{Cl} 2.33-5.90, P<0.001)$, exposure to sedative medications ( $\mathrm{RR}=3.54,95 \% \mathrm{Cl} 2.13-5.87, P<0.001)$, higher APACHE II score $(\mathrm{RR}=2.79,95 \% \mathrm{Cl} 1.98-3.95, P<0.001)$, thoracic surgery $(\mathrm{RR}=1.74,95 \% \mathrm{Cl} 1.09-2.78, P=0.021)$, and emergency surgery ( $R R=1.70,95 \% \mathrm{Cl} 1.09-2.65, P=0.019$ ) were independent risk factors of delirium in SICU.

Conclusions: Sepsis, exposure to sedative medications, higher APACHE II score, thoracic surgery, and emergency surgery were independent risk factors of delirium in Thai university-based surgical intensive care units.

Keywords: Incidence, Risk factor, Surgical intensive care unit, Delirium

\section{Background}

Delirium is defined as a disturbance of consciousness, cognition, attention, and perception, with these symptoms usually acute at the onset and with transient fluctuation over the course of the day [1]. Etiologies of delirium include ischemic brain injury [2], an imbalance of neurotransmitters [3], and peripheral inflammation of

\footnotetext{
* Correspondence: tanyong24@yahoo.com

${ }^{1}$ Department of Anesthesiology, Faculty of Medicine, Chiang Mai University,

110, Intavarorote Rd, Muang District, Chiang Mai 50200, Thailand

Full list of author information is available at the end of the article
}

the brain $[4,5]$. Delirium can lead to several consequences including prolonged mechanical ventilation [4], longer intensive care unit (ICU) admission [4, 5], longer hospitalization $[4,6]$, higher medical costs $[7,8]$, higher mortality rate $[4,6]$, as well as long-term cognitive impairment $[4,6]$.

The incidences of delirium in the medical and surgical intensive care units (SICU) vary from 11 to $70 \%$ depending on the types of surgical procedures, patient settings, and screening tools for diagnosis of delirium [9-13]. Surgical and medical patients have different pathophysiologies 
of disease processes and severity of illness; therefore, risk factors of delirium should be determined separately [4]. In addition, different types of surgical procedures could produce various degrees of central nervous system dysfunction and influence the occurrence of postoperative delirium [4]. Surgery is associated with delirium by inducing hypoperfusion [14], microembolism [15], or inflammatory response $[16,17]$. Anesthesia also increases risk of delirium. Some medications such as opioids, benzodiazepines, and anticholinergic drugs, which are commonly used for anesthetized patients, are associated with delirium [18]. In addition, anesthesia-related perioperative adverse events including intraoperative hypotension [13], transfusion of blood or blood products $[19,20]$, and moderate to severe postoperative pain [21] are also associated with postoperative delirium. These predisposing factors therefore may have an influence on the incidence of delirium in SICU, which is different from other ICU settings.

The studied risk factors of delirium in ICU are different among studies. These risk factors include elderly [10], higher Acute Physiology and Chronic Health Evaluation II score (APACHE II score) on admission [9, 22], emergency surgery [22], use of sedative and analgesic medications [12, 22], and trauma [22]. In addition, few studies have focused on risk factors of delirium in SICU $[12,13,22]$. The THAI-SICU study, a large, national multi-center study, recently reported ICU characteristics, overall outcomes, and incidences of adverse events including delirium [23]. The purpose of this study was to specifically determine the incidence and risk factors of delirium in THAI-SICU.

\section{Methods}

The prospective cohort study included patients of nine university-based surgical intensive care units in Thailand. These university SICU were across all regions of Thailand (Siriraj, Ramathibodi, King Chulalongkorn, Phramongkutklao, Sirinthorn Medical Center, Vajira, Maharaj Nakorn Chiang Mai, Srinakharinwirot, and Prince of Songkhla). The recruitment process began after approval was received from the Thai Joint Research Ethics Committee (JREC, no. 001/2011), each institution's Ethics Committee, and Institutional Review Board. All surgical patients with an age greater than 18 years who were admitted in a SICU between April 2011 and October 2012 were recruited in the study. Patients who had a sustained coma during admission, and required cardiopulmonary resuscitation with no return of spontaneous circulation, and patients who stayed in the ICU for less than $24 \mathrm{~h}$ were excluded from the study. In addition, neurosurgical patients and cardiac patients were also excluded because they were not admitted in most sites of SICU depending on individual hospital policies. Patients or their surrogates who met the inclusion criteria were informed about the study in order to obtain their consent. Data collections were divided into three phases including "on admission," "daily recording data," and "at discharge." The criteria for the diagnosis of delirium based on the Intensive Care Delirium Screening Checklists (ICDSC) [24] were discussed by all primary investigators. The assigned intensive care nurses of all sites were trained using ICDSC and completed the scale based on the information from the previous $24 \mathrm{~h}$. All the patients who were included in the study were followed up until being discharged from the ICU. If patients were admitted in the ICU for longer than 28 days, they were followed up until day 28 of the ICU admission. Sedative and analgesic medications were prescribed by the ICU physicians and titrated to achieve the target sedation and analgesic level by bedside nurses. The main outcome of this study was the determination of the incidence and risk factors of delirium. The details of individual patients with delirium included the date of diagnosis, date of recovery, frequency of delirium, diagnostic symptoms of delirium, types of delirium, and medical treatment. All case record forms and documents were further assessed and verified by the central data monitoring unit.

The demographic information included age, gender, comorbidity, American Society of Anesthesiologists physical status (ASA PS), smoking status, emergency surgery, sites of surgery, and the amount of blood and blood product administration. The APACHE II score and the sequential organ failure assessment score (SOFA score) were determined in order to assess the severity of the disease and the patient status, respectively. Other information included presence of sepsis, requirement of mechanical ventilation, laboratory investigation, exposure to sedative and analgesic medications, types of sedative and analgesic medications and route of drug administration, duration of ICU stay ( $\leq 48$ versus $>48 \mathrm{~h}$ ), hospital stay, and mortality rate.

The statistical analyses were analyzed using STATA, version 11.0 (Stata Corp LP, College Station, TX, USA). The descriptive data are presented as the number and percent for categorical data and mean \pm standard deviation, median, and 25 and $75 \%$ percentile for continuous data according to their distribution. Unpaired $t$ test, Mann-Whitney $U$ test, chi-square test, and Fisher exact probability test were used to detect the difference between the groups in the univariable analysis, as appropriate. The risk factors were analyzed using risk regression with a robust variance estimator and presented as risk ratio and $95 \%$ confidence interval. Any variables which had $P<0.20$ after the univariable risk regression and all other potential variables associated with the occurrence of delirium were included for the multivariable risk regression. The cut-off point of independent 
variables including age and serum albumin were determined by the maximum-likelihood estimation method in order to achieve the best discrimination between patients with and without delirium [25]. Sample sizes were calculated based on risk factors of previous studies, and the calculated sample size was 3200 with an accepted $\alpha$ of 5 and $80 \%$ power. $P<0.05$ was considered statistically significant.

\section{Results}

A total of 6548 patients were admitted to SICU during 19.7 months of recruitment period, and 2098 were excluded. A final number of 4450 patients were included in the analysis. The study flow is presented in Fig. 1. Almost $79 \%$ of patients (3496 of 4450) had a surgical procedure before their ICU admission. The proportion of patients undergoing elective surgical procedures accounted for $69.5 \%$ (2430 of 3496). The median length of ICU admission for patients with elective surgery and emergency surgery were $1(1-2)$ days and $3(2-6)$ days. The overall incidence of delirium in SICU was $3.6 \%$ (162 of 4450 patients, $95 \%$ CI 3.09-4.19\%). The incidences of delirium were even higher in patients with $>48 \mathrm{~h}$ admissions than those with $\leq 48 \mathrm{~h}$ (8.3\% (141 of $1685,95 \%$ CI $7.04-9.68 \%$ ) versus $0.7 \%$ (21 of 2967 , $95 \%$ CI 0.41-1.01\%), respectively).

Baseline characteristics and outcomes of patients with or without delirium are presented in Table 1. Delirious patients had a significantly higher age $(65.3 \pm 15.6$ versus $61.8 \pm 17.3$ years, $P=0.013)$, higher APACHE II score (16 (12-23) versus $10(7-15), P<0.001)$, and higher SOFA score $(5(2-8)$ versus $2(1-5), P<0.001)$. The

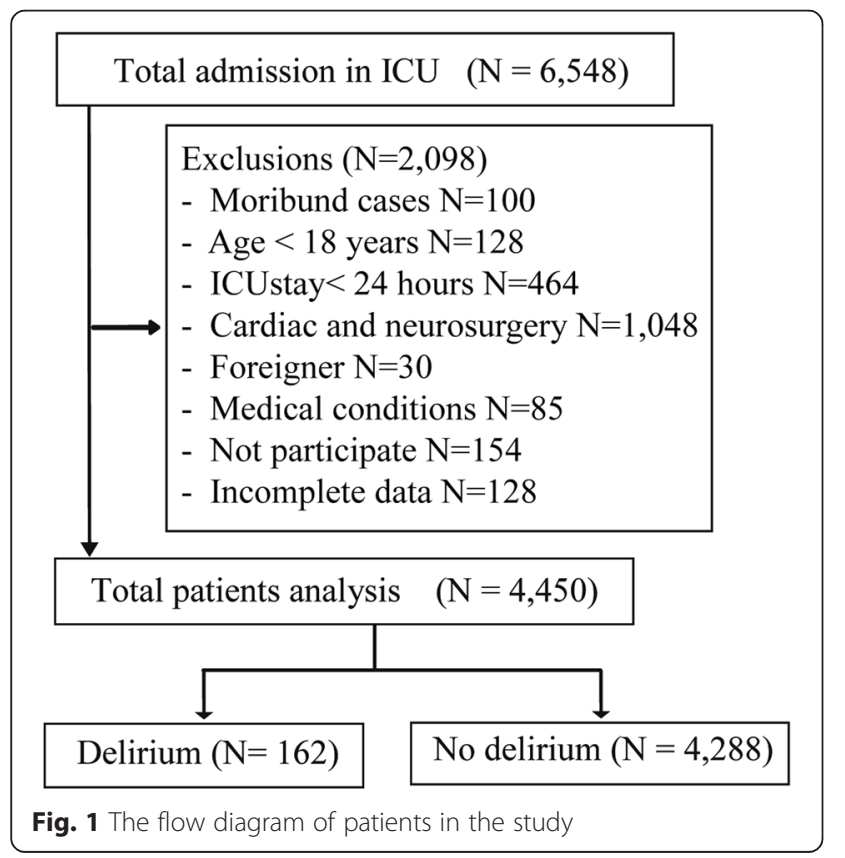

incidence of delirium differed by study sites ranging from 0 to $13.9 \%$. Delirious patients had significantly longer median ventilator days, longer duration of ICU stay, longer hospitalization, and higher ICU and 28-day mortality rate. Details of delirious patients are described in Table 2. Delirium was common on the day of ICU admission (27 of 162, $16.8 \%$ ) and the third day (20 of 162, $12.3 \%)$. The most common diagnostic symptoms of delirium included sleep disturbance (6\%), alteration of consciousness (3.1\%), disorientation (2.9\%), and inattention (2.9\%). Types of delirium included mixed (53\%), hyperactive (37\%), and hypoactive (10\%). The percentage of patients who were exposed to midazolam for controlling agitation during ICU admission was about $17 \%$ (740 of 4450). The proportion of patients who received a continuous infusion and intermittent bolus of midazolam was almost similar (50 \%).

Age $>70$ years, smoking, sites of surgical ICU, chronic renal failure, hypoalbuminemia, emergency surgery, thoracic surgery, sepsis, higher APACHE II score, on mechanical ventilator, and exposure to sedative medications increased the risk of postoperative delirium in univariable risk regression (Table 3 ). In multivariable risk regression analysis, sepsis (risk ratio $(\mathrm{RR})=3.70,95 \% \mathrm{CI}$ 2.33-5.90, $P<0.001)$, exposure to sedative drugs $(R R=$ 3.54, $95 \%$ CI 2.13-5.87, $P<0.001$ ), higher APACHE II score $(\mathrm{RR}=2.79,95 \% \mathrm{CI} 1.98-3.95, P<0.001)$, thoracic surgery $(\mathrm{RR}=1.74,95 \% \mathrm{CI} 1.09-2.78, P=0.021)$, and emergency surgery $(R R=1.70,95 \%$ CI $1.09-2.65, P=$ 0.019) were independent risk factors of delirium in SICU (Fig. 2).

\section{Discussion}

The overall incidence of delirium in SICU patients was $3.6 \%$ in the present study, and this increased up to $8.3 \%$ in patients admitted to SICU for longer than $48 \mathrm{~h}$. However, these incidences were considerably less than those reported by previous studies [9-13]. The majority of patients in this study had a short length of ICU stay $(\leq 48 \mathrm{~h})$, accounted for $67 \%$ of the total population. These patients mainly required postoperative continuous monitoring and critical management for a short period of time. Furthermore, they had significantly lower ASA PS, less comorbidity, and a lower APACHE II score, thereby being at approximately 12 times lower risk for delirium, compared to those with longer than $48 \mathrm{~h}$ of ICU stay (incidence 0.7 versus $8.3 \%$ ). This corresponds to a previous study showing that extended length of ICU stay almost 8.6 times was associated with increased risk of delirium [4].

The incidences of delirium among sites of surgical ICUs varied between 0 and $14 \%$ (Table 1), and there might be some heterogeneity among these sites during the study period. After exploration of patient characteristics among 
Table 1 Patient characteristics, details of surgery, laboratory investigation, and prognostic outcomes

\begin{tabular}{|c|c|c|c|}
\hline & Delirium $(n=162)$ & Non delirium $(n=4288)$ & $P$ \\
\hline \multicolumn{4}{|l|}{ Variables } \\
\hline Age (year) mean $\pm S D$ & $65.3 \pm 15.6$ & $61.8 \pm 17.3$ & 0.013 \\
\hline$<40(\mathrm{n}, \%)$ & $11(6.8)$ & $537(12.5)$ & \\
\hline 40-70 (n, \%) & $76(47.0)$ & $2175(50.7)$ & \\
\hline$>70(n, \%)$ & $75(46.2)$ & $1576(36.8)$ & \\
\hline Male $(n, \%)$ & $102(63.0)$ & $2505(58.4)$ & 0.249 \\
\hline Body mass index $\left(\mathrm{kg} / \mathrm{m}^{2}\right)($ mean $\pm \mathrm{SD})$ & $22.0 \pm 4.6$ & $23.0 \pm 5.7$ & 0.031 \\
\hline ASA PS (n, \%) & & & $<0.001$ \\
\hline$|-| \mid$ & $26(23.6)$ & 1291(39.0) & \\
\hline III & $58(52.7)$ & $1620(49.0)$ & \\
\hline $\mid \mathrm{V}-\mathrm{VI}$ & $26(23.6)$ & $392(12.0)$ & \\
\hline \multicolumn{4}{|l|}{ Comorbidity (n, \%) } \\
\hline Hypertension & $75(46.3)$ & $2130(49.7)$ & 0.399 \\
\hline Diabetes mellitus & $33(20.4)$ & $946(22.1)$ & 0.610 \\
\hline Coronary artery disease & $15(9.4)$ & $433(10.1)$ & 0.728 \\
\hline Congestive heart failure & $11(6.8)$ & $93(2.2)$ & $<0.001$ \\
\hline COPD & $21(12.9)$ & $184(4.3)$ & $<0.001$ \\
\hline Chronic renal failure & $25(15.4)$ & $406(9.5)$ & 0.012 \\
\hline Smoking history $(n, \%)$ & & & $<0.001$ \\
\hline Current smokers & $32(19.7)$ & $498(11.6)$ & \\
\hline Ex-smokers & $50(30.8)$ & $1054(24.6)$ & \\
\hline Non smokers & $80(49.4)$ & $2736(63.8)$ & \\
\hline Numbers of pack years median (P25-75) & $15.5(10-25)$ & $15(6-30)$ & 0.631 \\
\hline Numbers of operative patients $(n, \%)$ & $119(73.5)$ & 3377 (79.8) & 0.118 \\
\hline Sites of SICU $(n, \%)$ & & & $<0.001$ \\
\hline Site A (incidence $1.9 \%$ ) & $18(11.1)$ & $922(21.5)$ & \\
\hline Site B (incidence $1.2 \%$ ) & $5(3.1)$ & $404(9.4)$ & \\
\hline Site C (incidence $2.7 \%$ ) & $15(9.3)$ & $545(12.7)$ & \\
\hline Site D (incidence $1.9 \%$ ) & $8(5.0)$ & $402(9.3)$ & \\
\hline Site $\mathrm{E}$ (incidence $0.8 \%$ ) & $3(1.8)$ & $390(9.1)$ & \\
\hline Site F (incidence $0 \%$ ) & 0 & $139(3.2)$ & \\
\hline Site G (incidence $13.9 \%$ ) & $109(67.3)$ & $675(15.7)$ & \\
\hline Site H (incidence $0.8 \%$ ) & $3(1.8)$ & $368(8.6)$ & \\
\hline Site I (incidence $0.2 \%$ ) & $1(0.6)$ & $443(10.5)$ & \\
\hline Emergency surgery $(n, \%)$ & $79(66.4)$ & $987(29.2)$ & $<0.001$ \\
\hline \multicolumn{4}{|l|}{ Site of surgery $(n, \%)$} \\
\hline Upper abdomen & $56(34.6)$ & $1182(27.6)$ & 0.051 \\
\hline Lower abdomen & $43(26.5)$ & $1178(27.5)$ & 0.795 \\
\hline Thoracic & $15(9.8)$ & $162(3.8)$ & $<0.001$ \\
\hline Vascular & $5(3.1)$ & $134(3.1)$ & 0.978 \\
\hline Extremities & $14(8.6)$ & $371(8.3)$ & 0.883 \\
\hline Anus & $1(0.62)$ & $52(1.2)$ & 0.493 \\
\hline Other surgeries & $28(17.2)$ & $1209(28.2)$ & 0.001 \\
\hline Duration of surgery (min) median (P25-75) & $180(105-275)$ & $240(150-360)$ & $<0.001$ \\
\hline
\end{tabular}


Table 1 Patient characteristics, details of surgery, laboratory investigation, and prognostic outcomes (Continued)

\begin{tabular}{|c|c|c|c|}
\hline Amount of PRC transfusion (ml) median (P25-75) & $100(0-635)$ & $0(0-511)$ & 0.274 \\
\hline Amount of FFP transfusion (ml) median (P25-75) & $0(0-780)$ & $0(0-0)$ & $<0.001$ \\
\hline APACHE II median (P25-75) & $16(12-23)$ & $10(7-15)$ & $<0.001$ \\
\hline SOFA median (P25-75) & $5(2-8)$ & $2(1-5)$ & $<0.001$ \\
\hline Sepsis $(n, \%)$ & $109(67.3)$ & $779(18.2)$ & $<0.001$ \\
\hline Mechanical ventilation $(n, \%)$ & $141(87.0)$ & $2635(61.8)$ & $<0.001$ \\
\hline Albumin $(g / d l)($ mean $\pm S D)$ & $2.4 \pm 0.85$ & $2.8 \pm 0.80$ & $<0.001$ \\
\hline Hemoglobin $(\mathrm{g} / \mathrm{dl})($ mean $\pm \mathrm{SD})$ & $9.7 \pm 2.6$ & $10.6 \pm 2.1$ & $<0.001$ \\
\hline Blood sugar (mg\%) (mean \pm SD) & $144.0 \pm 72.0$ & $164.1 \pm 68.8$ & 0.013 \\
\hline $\mathrm{PaO} 2(\mathrm{mmHg})($ mean $\pm \mathrm{SD})$ & $144.0 \pm 72.1$ & $164.1 \pm 0.81$ & 0.013 \\
\hline Exposure to sedative drugs $(n, \%)$ & $110(67.9)$ & $932(21.7)$ & $<0.001$ \\
\hline Exposure to analgesic drugs $(n, \%)$ & $134(82.7)$ & $3683(85.9)$ & 0.256 \\
\hline ICU admission diagnosis ( $n, \%)$ & & & 0.005 \\
\hline Abdominal & $71(43.8)$ & $1728(40.3)$ & \\
\hline Cardiovascular & $31(19.1)$ & $662(15.4)$ & \\
\hline Respiratory & $17(10.5)$ & $335(7.8)$ & \\
\hline Renal & $10(6.2)$ & $356(8.3)$ & \\
\hline Other & $33(20.4)$ & $1207(28.2)$ & \\
\hline \multicolumn{4}{|l|}{ Prognostic outcomes } \\
\hline Ventilator days (days) median (P25-75) & $7(4-17)$ & $2(1-4)$ & $<0.001$ \\
\hline Length of ICU stay (days) median (P25-75) & $8(5-19)$ & $2(1-4)$ & $<0.001$ \\
\hline Duration of hospital stay (days) median(P25-75) & $22(14-34)$ & $15(9-26)$ & $<0.001$ \\
\hline ICU mortality $(n, \%)$ & $38(23.5)$ & $349(8.1)$ & $<0.001$ \\
\hline 28-day mortality $(n, \%)$ & $45(27.8)$ & $534(12.4)$ & $<0.001$ \\
\hline
\end{tabular}

Data are presented as mean \pm standard deviation (SD), median and 25 and $75 \%$ interquartile range, and number (\%)

ASA PS American Society of Anesthesiologists physical status, COPD chronic obstructive pulmonary disease, PRC packed red cell, FFP fresh frozen plasma, APACHE II Acute Physiology and Chronic Health Evaluation II, SOFA sequential organ failure assessment, ICU intensive care unit

the sites of SICU, the author found that the site of SICU (site G) which had the highest incidence of delirium had significantly higher percentage of septic patients (31.2 versus $3.3 \%$ ) and higher percentage of patients receiving sedative medications ( 22.1 versus $0.7 \%$ ) compared to the site (site F) with the lowest incidence of delirium. Both of these following factors were associated with an increased risk of delirium.

Patients with sepsis significantly had an increased risk of ICU delirium, corresponding to the findings of previous studies $[13,26]$. Sepsis can result in acute brain dysfunction and delirium by stimulation of inflammatory cytokine, and endothelial damage, thereby increasing permeability of the blood-brain barrier and causing impairment of capillary blood flow [18, 27]. In addition, these cytokines can cross the blood-brain barrier, increase permeability of the brain tissue, and produce an abnormality of the electroencephalography $[18,28]$. Previous studies found that there was an association of delirium and an increased level of serum biomarkers such as neuron-specific enolase or s-100 $\beta$ during severe infection $[18,27]$. The knowledge of serum biomarkers helps clinicians understand the relationship between mechanisms and the development of delirium. However, the measurement of these biomarkers is not routinely used in daily practice.

Sedative and analgesic medications are commonly used for critically ill patients for reducing agitation, anxiety, and pain related to surgery and procedure, improving patient and mechanical ventilation synchronization and reducing physiological stress responses [29]. Similar to the results of previous studies, our findings revealed that exposure to sedative medications increased the risk of delirium in ICU almost three times [9, 20, 22, 30]. Also, the incidence of delirium was significantly higher in patients receiving midazolam than those who were not exposed to midazolam (10.3 versus $2.3 \%, P<0.001$ ). Benzodiazepine, a gamma aminobutyric acid, can contribute to the occurrence of delirium via several mechanisms including the disturbance of normal sleep pathway, direct impairment of memory function, and alteration of the level of neurotransmitters [31]. According 
Table 2 Characteristics of delirious patients $(n=162)$

\begin{tabular}{ll}
\hline Factors & Number (percent) \\
\hline Duration of delirium (days) median (P25-75) & $3(1-5)$ \\
1 & $114(96.6)$ \\
2 & $4(3.4)$ \\
Treatment of delirium & \\
Benzodiazepine & $48(40.7)$ \\
Antipsychotic drugs & $40(34)$ \\
a2 agonist & $1(0.8)$ \\
Psychiatrist consultation & $18(15.2)$ \\
Impaired vision & $16(13.7)$ \\
Impaired hearing & $13(11)$ \\
History of chronic alcoholism & $20(17.7)$ \\
Smoking status & $47(41.6)$ \\
Physical restraint & $69(59)$ \\
Lab abnormality & \\
Acidosis & $22(18.8)$ \\
Hypoalbuminemia & $62(53)$ \\
Received blood or blood product transfusion & $62(55.8)$ \\
\hline
\end{tabular}

The data are presented as median and 25 and $75 \%$ interquartile range and number (\%) to the current guidelines of the American College of Critical Care Medicine for management of pain and agitation [32], all patients should be frequently assessed for the level of sedation with valid and reliable screening tools in order to maintain an adequate level of depth of sedation during anesthesia and in ICU stay. Providing daily interruption of sedative medication and administration of an alternative sedative drug such as $\alpha 2$ adrenergic agonist are recommended [32].

The APACHE II score represents disease severity of individual patients. Corresponding to the findings of previous studies $[9,30]$, the present study found that a higher APACHE II score was a strong risk factor of delirium in SICU $(R R=2.12)$. The authors categorized patients according to their APACHE II score and classified them into two groups by using a cut-off value of 24 before inclusion into the final model during regression analysis. Patients with an APACHE II score higher than 24 indicated high-risk patients. Van Rompaey et al. [20] reported that risk of delirium increased about 2.5 times by univariable regression analysis; however, they could not find any association between the APACHE II score and delirium by multivariable regression analysis. Highrisk patients should receive an appropriate medical optimization as well as regular monitoring for delirium.

The present study also found that thoracic surgery increased risk of delirium in ICU. The effect of one lung ventilation during thoracic surgery could increase risk of postoperative delirium by several mechanisms including an activation of pulmonary inflammatory response and

Table 3 Univariable risk regression of ICU delirium

\begin{tabular}{|c|c|c|c|}
\hline Risk factors & Risk ratio & $95 \% \mathrm{Cl}$ & P \\
\hline \multicolumn{4}{|l|}{ Age group (years) } \\
\hline$<40(\mathrm{n}, \%)$ & 1.00 & & Reference \\
\hline $40-70(n, \%)$ & 1.68 & $0.89-3.16$ & 0.107 \\
\hline$>70(n, \%)$ & 2.26 & $1.20-4.26$ & 0.011 \\
\hline Male & 1.20 & $0.87-1.65$ & 0.259 \\
\hline Smoking & 1.77 & $1.30-2.40$ & $<0.001$ \\
\hline Chronic renal failure & 1.70 & $1.11-2.61$ & 0.015 \\
\hline Hypoalbuminemia $(<2.5$ versus $\geq 2.5 \mathrm{~g} / \mathrm{dl}$ ) & 1.92 & $1.37-2.67$ & $<0.001$ \\
\hline Emergency surgery & 4.50 & $3.08-6.58$ & $<0.001$ \\
\hline Upper abdominal surgery & 1.37 & $0.99-1.89$ & 0.056 \\
\hline Lower abdominal surgery & 0.95 & $0.67-1.35$ & 0.799 \\
\hline Thoracic surgery & 2.46 & $1.45-4.91$ & 0.001 \\
\hline Higher APACHE II score (>24 versus $\leq 24)$ & 1.09 & $1.07-1.11$ & $<0.001$ \\
\hline Sepsis & 8.24 & $5.94-11.45$ & $<0.001$ \\
\hline Mechanical ventilation & 4.00 & $2.53-6.29$ & $<0.001$ \\
\hline Exposure to sedative medications & 7.01 & $5.05-9.74$ & $<0.001$ \\
\hline Exposure to analgesic medications & 0.83 & $0.56-1.25$ & 0.386 \\
\hline
\end{tabular}

APACHE II Acute Physiology and Chronic Health Evaluation II 


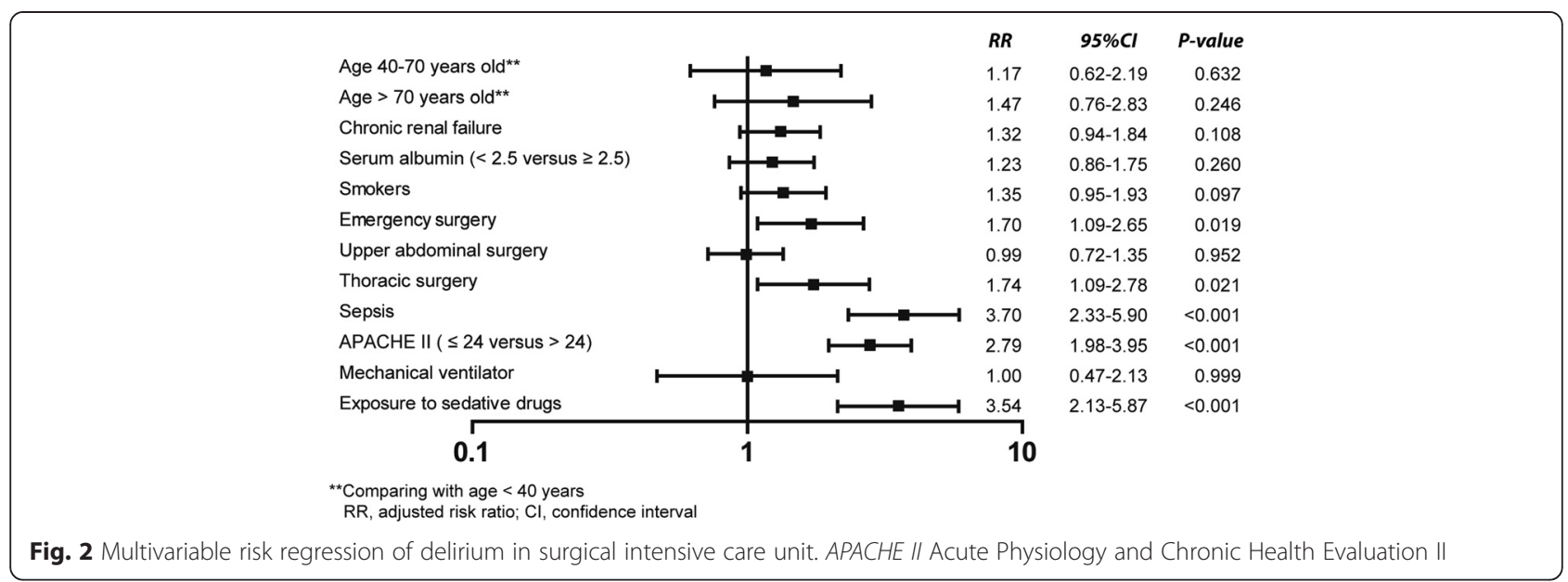

cytokines [33], causing several physiological disturbances such as hypoxia or surgical stress [34], and aggravating proinflammatory response [34].

Emergency surgery was an independent risk factor of delirium in ICU in this study. Previous studies also proposed that emergency surgery increased risk of postoperative morbidity and morbidity and increased an incidence of delirium compared to those receiving elective surgery $[22,35]$. Although some risk factors such as age [22, 30], mechanical ventilation [20], and opioid exposure [12] have been demonstrated as a risk factor of delirium in ICU, the present study could not find any association between these independent risk factors and delirium.

The present study was the largest, multi-center, prospective cohort study and determined the incidence and risk factors of delirium on surgical ICU in Thailand. The results of this study could be used as a reference and benchmark for Thai academic hospitals, SICU settings in this study. First, this study performed a single delirium assessment per day, which was considerably less than the recommended guideline [32]. This could lead to an underestimation of its incidence due to the fluctuation of symptoms over the course of the day. Secondly, this study did not assess the amount of sedative medications; therefore, we could not demonstrate the causal relationship between sedative medication and delirium. Finally, some potential risk factors of delirium in ICUs such as preoperative cognitive impairment, visual or auditory impairment, and limitations of functional capacity were not included in this study.

\section{Conclusions}

The present study found that sepsis, exposure to sedative medications, higher APACHE II scores, thoracic surgery, and emergency surgery were significant risk factors of delirium in Thai university-based SICU. An identification of high-risk patients, appropriate medical optimization, and careful adjusting of sedative medications according to the level of sedation could reduce an incidence and severity of delirium in ICU.

\section{Abbreviations}

APACHE II score: Acute Physiology and Chronic Health Evaluation II score; ASA PS: American Society of Anesthesiologists physical status; Cl: confidence interval; ICDSC: Intensive Care Delirium Screening Checklists; ICU: intensive care unit; JREC: Joint Research Ethics Committee; RR: risk ratio; SICU: surgical intensive care unit; SOFA: sequential organ failure assessment score.

\section{Competing interests}

The authors declare that they have no competing interests.

\section{Authors' contributions}

TP participated in the study design, performed the statistical analysis, and drafted the manuscript. KC and OC participated in the study design, performed the statistical analysis, and revised the manuscript. TT, PW, and SK participated in the co-ordination and specific data review. All authors read and approved the final manuscript.

\section{Acknowledgments}

The authors would like to thank Professor Dr. Somrat Charuluxananan and Assoc. Prof. Yodying Punjasawadwong for their advice and Assoc. Prof. Suree Lekawanvijit for her help in editing the manuscript. This study was supported through funding by the Royal College of Anesthesiology of Thailand, National Research Council of Thailand (NRCT), Mahidol University, King Chulalongkorn University, Chiang Mai University, Khon Kaen University, Prince of Songkhla University, Bangkok Metropolis University,

Phramongkutklao Hospital, and Srinakharinwirot University. The data processing was performed by the Medical Research Network of the Consortium of Thai Medical Schools (MedResNet). The THAI-SICU Study Group include Sunthiti Morakul, M.D., Department of Anesthesiology, Faculty of Medicine, Ramathibodi Hospital, Mahidol University, Bangkok, Pusit Fuengfoo, M.D., Department of Surgery, Phramongkutklao Hospital, Bangkok, Thailand, Sunisa Chatmongkolchart, M.D., Department of Anesthesiology, Faculty of Medicine, Prince of Songkhla University, Songkhla, Osaree Akaraborworn, M.D., Department of Surgery, Faculty of Medicine, Prince of Songkhla University, Songkhla, Chompunoot Pathonsamit, M.D. and Sujaree Poopipatpab, M.D., Department of Anesthesiology, University of Bangkok Metropolis and Vajira Hospital, Bangkok, Sarinya Chanthawong, M.D. and Waraporn Chau-In, M.D., Department of Anesthesiology, Faculty of Medicine, Khon Kaen University, Khon Kaen, and Chaiyapruk Kusumaphanyo, M.D. and Phakapan Buppha, M.D., Department of Anesthesiology, Faculty of Medicine, Srinakharinwirot University, Nakorn Nayok.

\section{Author details}

${ }^{1}$ Department of Anesthesiology, Faculty of Medicine, Chiang Mai University, 110, Intavarorote Rd, Muang District, Chiang Mai 50200, Thailand. 
${ }^{2}$ Department of Surgery, Faculty of Medicine, Chiang Mai University, Chiang Mai 50200, Thailand. ${ }^{3}$ Department of Anesthesiology, Faculty of Medicine, Siriraj Hospital, Mahidol University, Bangkok 10700, Thailand. ${ }^{4}$ Department of Anesthesiology, Faculty of Medicine, King Chulalongkorn Memorial Hospital, Bangkok 10330, Thailand. ${ }^{5}$ Department of Anesthesiology, Phramongkutklao Hospital, Bangkok 10400, Thailand.

\section{Received: 6 September 2015 Accepted: 17 November 2015} Published online: 02 December 2015

\section{References}

1. American Psychiatric Association. Diagnostic and Statistical Manual of Mental Disorders (DSM-IV-TR). 4th ed. Washington DC: American Psychiatric Association; 2000.

2. Fong TG, Bogardus ST, Daftary A, Auerbach E, Blumenfeld H, Modur S, et al. Cerebral perfusion changes in older delirious patients using 99mTc HMPAO SPECT. J Gerontol A Biol Sci Med Sci. 2006:61:1294-9.

3. Han L, McCusker J, Cole M, Abrahamowicz M, Primeau F, Élie M. Use of medications with anticholinergic effect predicts clinical severity of delirium symptoms in older medical inpatients. Arch Intern Med. 2001;161:1099-105.

4. van den Boogaard M, Schoonhoven L, van der Hoeven JG, van Achterberg T, Pickkers P. Incidence and short-term consequences of delirium in critically ill patients: a prospective observational cohort study. Int J Nurs Stud. 2012;49:775-83.

5. Salluh J, Soares M, Teles J, Ceraso D, Raimondi N, Nava V, et al. Delirium epidemiology in critical care (DECCA): an international study. Crit Care. 2010;14:R210.

6. Ely EW, Shintani A, Truman B, Speroff T, Gordon SM, Harell FE, et al. Delirium as a predictor of mortality in mechanically ventilated patients in the intensive care unit. JAMA. 2004:291:1753-62.

7. Franco K, Litaker D, Locala J, Bronson D. The cost of delirium in the surgical patient. Psychosomatics. 2001;42:68-73.

8. Milbrandt EB, Deppen S, Harrison PL, Shintani AK, Speroff T, Stiles RA, et al. Costs associated with delirium in mechanically ventilated patients. Crit Care Med. 2004;32:955-62.

9. Ouimet S, Kavanagh BP, Gottfried SB, Skrobik Y. Incidence, risk factors and consequences of ICU delirium. Intensive Care Med. 2007;33:66-73.

10. Yamaguchi T, Tsukioka E, Kishi Y. Outcomes after delirium in a Japanese intensive care unit. Gen Hosp Psychiatry. 2014;36:634-6.

11. Robinson $T$, Raeburn CD, Tran ZV, Angles EM, Brenner LA, Moss M. Postoperative delirium in the elderly: risk factors and outcomes. Ann Surg. 2009;249:173-8.

12. Pandharipande $P$, Cotton BA, Shintani A, Thompson J, Pun BT, Morris Jr JA, et al. Prevalence and risk factors for development of delirium in surgical and trauma intensive care unit patients. J Trauma. 2008;65:34-41.

13. Aldemir M, Ozen S, Kara I, Sir A, Bac B. Predisposing factors for delirium in the surgical intensive care unit. Crit Care. 2001;5:265-70.

14. Marcantonio ER, Goldman L, Orav EJ, Cook EF, Lee TH. The association of intraoperative factors with the development of postoperative delirium. Am J Med. 1998;105:380-4.

15. Hogue CW, Palin CA, Arrowsmith JE. Cardiopulmonary bypass management and neurologic outcomes: an evidence-based appraisal of current practices. Anesth Analg. 2006;103:21-37.

16. Rasmussen LS, Christiansen M, Rasmussen H, Kristensen PA, Moller JT. Do blood concentrations of neurone specific enolase and S-100 beta protein reflect cognitive dysfunction after abdominal surgery? ISPOCD Group. $\mathrm{Br} J$ Anaesth. 2000;84:242-4.

17. Ritter C, Tomasi C, Dal-Pizzol F, Pinto B, Dyson A, de Miranda A, et al. Inflammation biomarkers and delirium in critically ill patients. Crit Care 2014;18:R106.

18. Gunther ML, Morandi A, Ely EW. Pathophysiology of delirium in the intensive care unit. Crit Care Clin. 2008;24:45-65.

19. Angles EM, Robinson TN, Biffl WL, Johnson J, Moss M, Tran ZV, et al. Risk factors for delirium after major trauma. Am J Surg. 2008;196:864-70.

20. Van Rompaey B, Elseviers M, Schuurmans M, Shortridge-Baggett L, Truijen S, et al. Risk factors for delirium in intensive care patients: a prospective cohort study. Crit Care. 2009;13:R77.

21. Vaurio LE, Sands LP, Wang Y, Mullen EA, Leung JM. Postoperative delirium: the importance of pain and pain management. Anesth Analg. 2006;102:1267-73.
22. Serafim RB, Dutra MF, Saddy F, Tura B, de Castro JE, Villarinho LC, et al. Delirium in postoperative nonventilated intensive care patients: risk factors and outcomes. Ann Intensive Care. 2012;2:51.

23. Chittawatanarat K, Chaiwat O, Morakul S, Pipanmekaporn T, Thawitsri T, Wacharasint $P$, et al. A multi-center Thai university-based surgical intensive care units study (THAI-SICU study): methodology and ICU characteristics. J Med Assoc Thai. 2014;97 Suppl 1:S45-54.

24. Bergeron N, Dubois MJ, Dumont M, Dial S, Skrobik Y. Intensive Care Delirium Screening Checklist: evaluation of a new screening tool. Intensive Care Med. 2001;27:859-64.

25. Vittinghoff E, Shiboski SC, Glidden DV, McCulloch CE. Logistic regression. In: Vittinghoff E, Shiboski SC, Glidden DV, McCulloch CE, editors. Regression methods in biostatistics. New York: Springer; 2005. p. 157-209.

26. Lin SM, Liu CY, Wang CH, Lin HC, Huang CD, Huang PY, et al. The impact of delirium on the survival of mechanically ventilated patients. Crit Care Med. 2004;32:2254-9.

27. Khan BA, Zawahiri M, Campbell NL, Boustani MA. Biomarkers for delirium-a review. J Am Geriatr Soc. 2011;59:S256-61.

28. Stocchetti N. Brain and sepsis: functional impairment, structural damage, and markers. Anesth Analg. 2005;101:1463-4.

29. Pandharipande PP, Patel MB, Barr J. Management of pain, agitation, and delirium in critically ill patients. Pol Arch Med Wewn. 2014;124:114-23.

30. Pandharipande P, Shintani A, Peterson J, Pun BT, Wilkinson GR, Dittus RS, et al. Lorazepam is an independent risk factor for transitioning to delirium in intensive care unit patients. Anesthesiology. 2006;104:21-6.

31. Sanders RD, Maze M. Contribution of sedative-hypnotic agents to delirium via modulation of the sleep pathway. Can J Anesth. 2011;58:149-56.

32. Barr J, Fraser GL, Puntillo K, Ely EW, Gélinas C, Dasta JF, et al. Clinical practice guidelines for the management of pain, agitation, and delirium in adult patients in the intensive care unit: executive summary. Am J Health Syst Pharm. 2013;70:53-8.

33. Sugasawa Y, Yamaguchi K, Kumakura S, Murakami T, Kugimiya T, Suzuki K, et al. The effect of one-lung ventilation upon pulmonary inflammatory responses during lung resection. J Anesth. 2011;25:170-7.

34. Hemmerling TM, Bluteau MC, Kazan R, Bracco D. Significant decrease of cerebral oxygen saturation during single-lung ventilation measured using absolute oximetry. Br J Anaesth. 2008;101:870-5.

35. Ansaloni L, Catena F, Chattat R, Fortuna D, Franceschi C, Mascitti P, et al. Risk factors and incidence of postoperative delirium in elderly patients after elective and emergency surgery. Br J Surg. 2010;97:273-80.

\section{Submit your next manuscript to BioMed Central and we will help you at every step:}

- We accept pre-submission inquiries

- Our selector tool helps you to find the most relevant journal

- We provide round the clock customer support

- Convenient online submission

- Thorough peer review

- Inclusion in PubMed and all major indexing services

- Maximum visibility for your research

Submit your manuscript at www.biomedcentral.com/submit
C) BioMed Central 